\title{
XLVI. Resonance experiments with the longest heat-waves
}

\section{R.W. Wood}

To cite this article: R.W. Wood (1913) XLVI. Resonance experiments with the longest heatwaves, Philosophical Magazine Series 6, 25:148, 440-443, DOI: 10.1080/14786440408634182

To link to this article: http://dx.doi.org/10.1080/14786440408634182

曲 Published online: 08 Jun 2010.

Submit your article to this journal $\pi$

Џ Article views: 4

Q View related articles $\sqsubset$ 


\section{$\left[\begin{array}{ll}440 & ]\end{array}\right.$}

XLVI. Resonance Experiments with the Longest Heat-Waves. By R. W. WOoD, Professor of Experimental Physics, Johns Hopkins University, and Adams Research Fellow of Columbia University *.

[Plate III.]

IN the autumn of $1910 \mathrm{H}$. Rubens and R. W. Wood suc1 ceeded in isolating and measuring the longest heat-waves known at the time, by a method based on the circumstance that the refractive index of quartz is much higher for these waves than for light-waves and the shorter heat-waves. A description of the method, which may be termed "focal isolation," will be found in my 'Physical Optics,' 2nd edition (1912) ; also Phil. Mag. Feb.1911. The waves were emitted from a Welsbach mantle and had a wave-length of over onetenth of a millimetre $(112 \mu)$, and Rubens and von Baeyer subsequently obtained by the same method waves of greater length $(0 * 3 \mathrm{~mm}$.) from the quartz-mercury arc. As the shortest electric waves obtained by von Baeyer have a length of about $2 \mathrm{~mm}$., it will be seen that the gap between the electric and optical spectrum is very nearly filled up.

The very great length of these heat-waves makes it possible to try experiments analogous to the experiments made by various investigators on the action of metallic resonators on electromagnetic waves. I have already commenced an investigation of this subject, and the results obtained up to the present time will be reported in this paper.

The first experiments were made with very minute particles of metallic copper deposited on quartz plates. The metal can be obtained from the chemists in the form of a very fine powder, and if some of this is violently shaken in a tall glass jar, the finest particles remain suspended in the air. If the jar is then inverted over the quartz plate, and allowed to stand for a few minutes, a beautifully regular deposit settles on the plate. Treating the plate to the process four or five times builds up a deposit which is almost opaque to light, the slight amount which struggles through being of a greenish colour. To my surprise I found that eren these very heavy deposits, which by actual measurement transmitted only two or three per cent. of visible light, were perfectly transparent to the long heat-waves. The same amount of metal, in fact a much less quantity, in the form of a uniform film would be

\footnotetext{
* Communicated by the Author.
} 
absolutely opaque to the heat-waves, for we know that the reflecting power of a metal is practically 100 per cent. for all waves longer than ahout $10 \mu$. The same thing is true of carbon deposits. When studying the transmission of the waves through various substances in collaboration with Rubens, it was found that a deposit of smoke on a quartz plate, so dense that the Welsbach mantle was invisible through it, transmitted over 95 per cent. of the heat radiation. It seemed of interest to ascertain the relation existing between the transparency of a layer of metallic particles, and the size of the particles, in other words, to carry out experiments analogous to those on the action of tinfoil strips of various size (mounted on glass) on electromagnetic waves. Various methods may be used for the preparation of the resonator plates. We may deposit a film of the metal on a quartz plate and then rule it into small squares or rectangles with a diamond point, on a dividing-engine. This method was tried over fifteen years ago by Rubens and Nichols; much shorter heat-waves were then available $(12 \mu)$, and though the experiments appeared to indicate electromagnetic resonance, they were not as satisfying as was to be desired.

Another method is to prepare metal particles of uniform size and deposit these over the quartz surface.

This was the method first adopted in the present case. I first tried blowing a fusible alloy into a fine spray with an atomizer (the method used by Professor Millikan and his colleagues).

Very perfect spherical droplets can be obtained in this way, but difficulties were found in sorting them out into groups of uniform size of particles, and in depositing them (after sorting) with any regularity of distribution. It then occurred to me to condense a metallic vapour on the quartz plates in the form of a "dew." This method worked admirably. A small quantity of mercury was heated in a beaker, and the quartz plate suspended in a horizontal position about $2 \mathrm{~cm}$. above the surface of the metal. Very regular deposits were obtained in this way, the size of the globules varying with the duration of the exposure of the plate to the metallic fumes.

Photographs of the deposits taken with a microscope are reproduced on Pl. III. figs. 1 to 6 inclusive. A photograph of a "stage micrometer" scale is reproduced immediately below the figures. One division on this scale corresponds to $0.01 \mathrm{~mm}$. As is apparent from the photographs, the diameters of the drops of a given deposit are fairly constant and their distribution is pretty regular. 


\section{Resonance Experiments with the Longest Heat-Waves.}

The diameters are as follows on the plates photographed: fig. 1 ( $\cdot 005 \mathrm{~mm}$.), fig. 2 (.01 mm.), fig. $3(\cdot 02$ to $\cdot 03 \mathrm{~mm}$.), fig. 4 (.03 to $.04 \mathrm{~mm}$.), fig. 5 (.05 mm.), fig. 6 (.06 to $.08 \mathrm{~mm}$.). Thus the smallest particles used had a diameter equal to about $1 / 20$ of a wave-length, and the largest $2 / 3$ of a wave-length. The transmission of each plate of resonators was compared with that of a clean plate of quartz of the same thickness, for radiation of wave-length $1 \mu$, and the $112 \mu$ waves obtained by focal isolation. 'The transmission of the $1 \mu$ waves gives us a rough measure of the ratio of the covered to the uncovered portion of the surface, for the metal droplets act merely as opaque obstacles for these very short heat-waves. The observations were made with Dr. Pfund's infrat-red spectrometer, which he kindly placed at my disposal. The transmission of the $112 \mu$ waves was measured with a radiomicrometer of the same type as the one used in the experiments carried out in collaboration with Professor Rubens. The instrument was made for me by Herr Obst, the mechanician of the Berlin Physical Institute, but as it arrived with the thermo-electric junction damaged it was fitted up with a much lighter junction, which Dr. Pfund made for me, with perhaps $1 / 10$ of the heat capacity of the original one. It proved far more sensitive than the one used in the earlier work, giving about double the deflexion for the same period, with the $112 \mu$ waves obtained under identical conditions. The transmissions of a number of resonator plates are given in the following table :-

\begin{tabular}{|c|c|c|c|}
\hline & $\begin{array}{c}\text { Percentage } \\
\text { transmitted of } \\
\text { Radiation } \lambda=1 \mu .\end{array}$ & $\begin{array}{c}\text { Percentage } \\
\text { transmitted of } \\
\text { Radiation } \lambda=112 \mu .\end{array}$ & $\begin{array}{l}\text { Diameter of } \\
\text { Spheres. }\end{array}$ \\
\hline Fig. 1. & 45 & 100 & $.005 \mathrm{~mm}$ \\
\hline Fig. 2. & 26 & 95 & .01 \\
\hline Fig. 3. & 32 & 82 & $\cdot 02-03$ \\
\hline Fig. 4. & 45 & 58 & $\cdot 03-04$ \\
\hline Fig. 5. & 26 & 50 & $\cdot 05$ \\
\hline Fig. 6. & 30 & 27 & $\cdot 07-08$ \\
\hline
\end{tabular}

This table shows us that the droplets have no effect on the very long heat-waves until their diameter exceeds about $1 / 10$ of a wave-length. When the diameter is about $\frac{1}{4} \lambda$, as in fig. 4 , the transmission is not much greater for the $112 \mu$ waves than for the short ones. For the case shown in fig. 5 we have slightly larger spheres packed much closer together however, so that we have only 26 per cent. transmission for short waves; even now 60 per cent. of the energy of the $112 \mu$ radiation is passed by the plate. On a further increase of size, fig. 6 , the transmission is about the same for both wave-lengths. 
It appears to me to be worthy of remark that in no case is the opacity of the resonator plate greater for the long waves than for the short, in other words, each sphere is able to stop only that portion of the energy of the wave-front which falls upon it, in other words it does not drain the region surrounding it. This rather surprised me, for I had expected to find that with spheres of a certain size we should have moderate transparency for short waves and absolute opacity for the long ones.

I have been unable to find any investigation, either theoretical or experimental, of the action of spherical metal obstacles arranged in close proximity, upon electromagnetic waves, so that there is nothing with which to compare these results at the present time.

Investigations have, however, been made with linear rect. angular resonators, and I accordingly commenced experimenting with these. Silver was deposited on quartz and ruled into small squares with a dividing-engine, but I found that the film was quite as opaque to the $112 \mu$ waves after the cross ruling, as before, though the size of the squares was less than $1 / 10$ of the wave-length. A photograph of the film with one set of rulings is reproduced on Pl. III. fig. 8. This I have alluded to in a previous paper on Electron Atmospheres of Metals (Phil. Mag. Aug. 1912). It was found that the ruling had not altered the conductivity of the film, though the microscope indicated that the diamond had cut clear through the silver down to the quartz. If the conductivity is not affected we should not expect the opacity of the films to be decreased. The question as to why the conductivity is not affected was discussed in the previous paper. In order to obtain satisfactory results with resonators prepared in this way, it will be necessary to devise a way of making wider cuts, and leaving less metal between them, and experiments in this direction are now in progress.

XLVII. The Satellites of the Mercury Lines. By R. W. Wood, Professor of Experimental Physics, Johns Hopkins University, and Adams Research Fellow of Columbia University*.

\section{[Plate [V.]}

7 THERE have been many discrepancies among the obser-

1 vations, made by different observers, of the structure of the mercury lines, and even at the present time, with all of the work which has been done with echelons and interference

* Communicated by the Author. 
Woop.
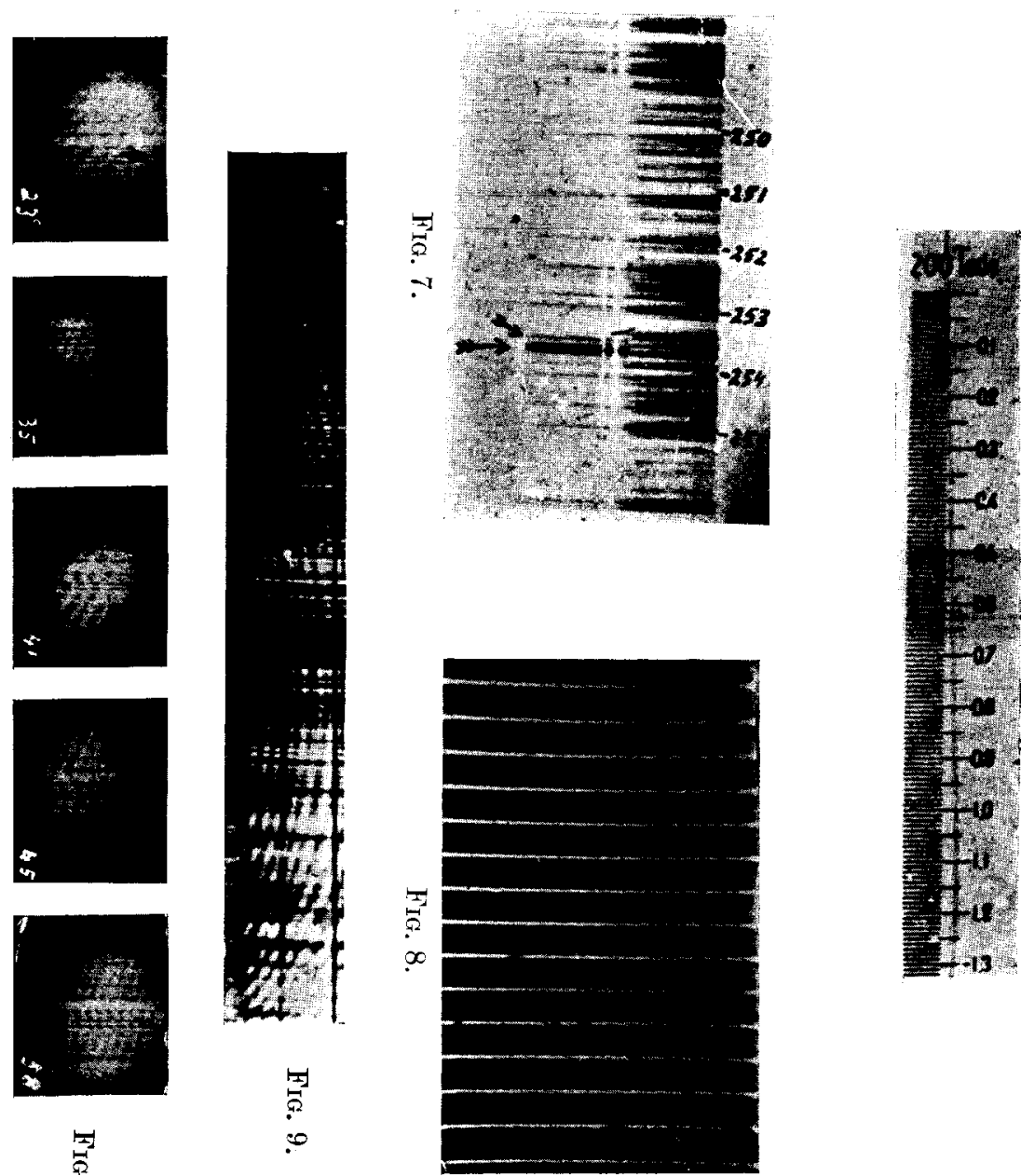

团

官 
Phil. Mag. Ser. 6, Vol. 25, Pl. III.
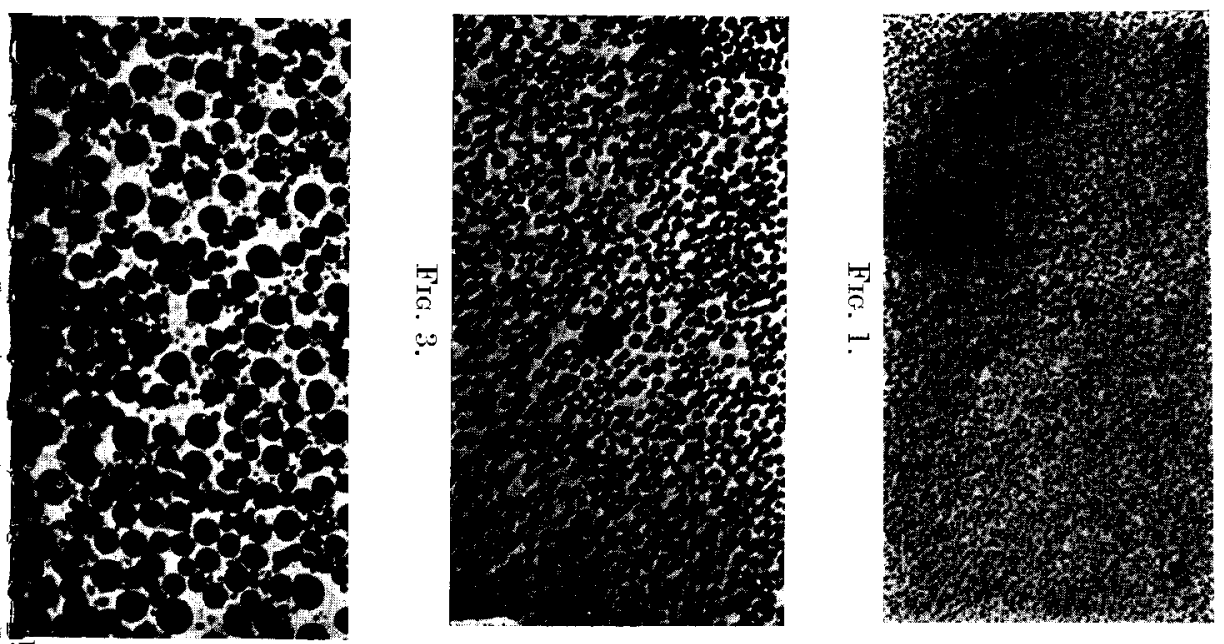

0
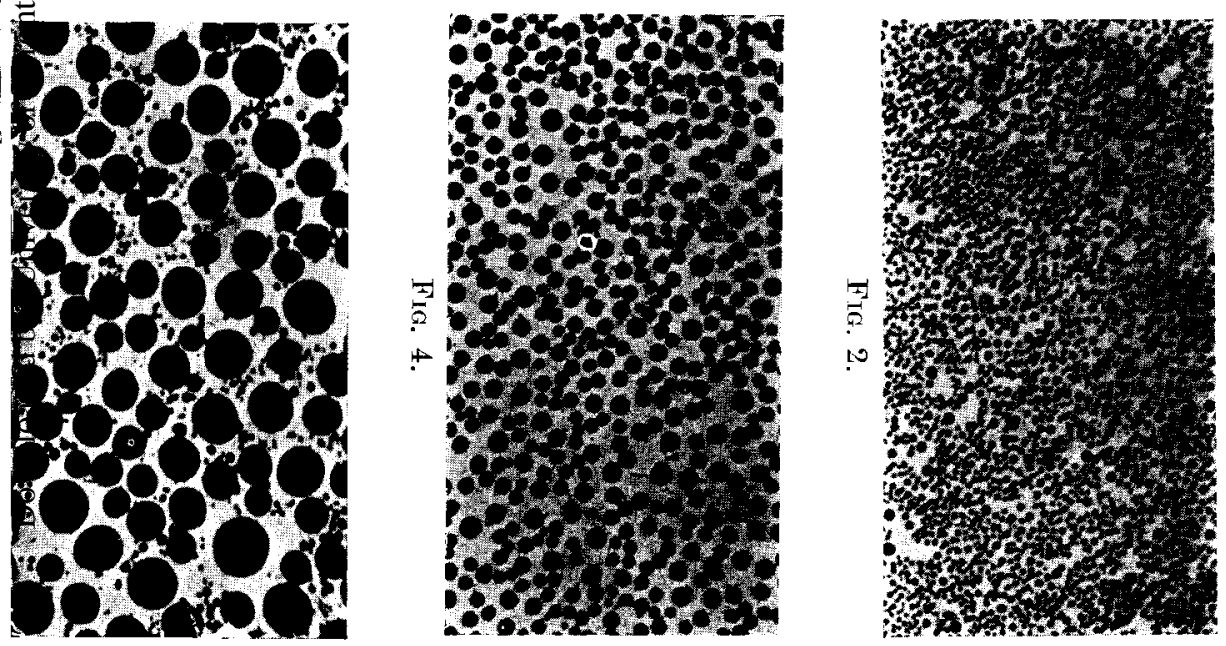